\title{
PRESCRIPTION PATTERN OF ANTIEPILEPTIC DRUGS IN SOUTHERN PAKISTAN: A RETROSPECTIVE COHORT STUDY IN TERTIARY CARE CENTRES
}

\author{
MUHAMMAD ARIF ASGHAR ${ }^{1 *}$, AHAD ABDUL REHMAN ${ }^{2}$, MUHAMMAD LIAQUAT RAZA $^{3,4}$, \\ NAZISH MUMTAZ ${ }^{5}$, MUHAMMAD ASIF ASGHAR ${ }^{6}$, YOUSRA SHAFIQ $^{1}$, KAMRAN KHAN $^{1}$ \\ ${ }^{I}$ Department of Pharmaceutics, Faculty of Pharmacy, Jinnah Sindh Medical University, Rafiqui H.J Shaheed Road, Karachi- \\ 75510, Pakistan \\ ${ }^{2}$ Department of Pharmacology, Faculty of Pharmacy, Jinnah Sindh Medical University, Rafiqui H.J Shaheed Road, Karachi- \\ 75510, Pakistan \\ ${ }^{3}$ Department of Pharmacology, Faculty of Pharmacy, Hamdard University, Karachi, Sharae Madinat Al-Hikmah, \\ Muhammad Bin Qasim Avenue, Karachi-74600, Sindh-74200, Pakistan \\ ${ }^{4}$ Institute of Neurophysiology, Charité - Universitätsmedizin Berlin, Germany \\ ${ }^{5}$ Department of Pharmaceutics, Faculty of Pharmacy, Benazir Bhutto Shaheed University, Lyari Karachi, Pakistan \\ ${ }^{6}$ Food and Feed Safety Laboratory, Food and Marine Resources Research Centre, PCSIR Laboratories Complex, Shahrah-e- \\ Salimuzzaman Siddiqui, Off University Road, Karachi-75280, Sindh-74200, Pakistan
}

*corresponding author: m.arifasgher@hotmail.com

Manuscript received: November 2018

\begin{abstract}
Epilepsy is the most occurring neurological disorder after stroke. Prevalence of epilepsy is about 9.99 per 1000 population in Pakistan. In recent years, about 14 new antiepileptic drugs (AEDs) have been marketed. Irrational drugs prescribing might decrease patient adherence with therapy and cause therapeutic failure. The aim of the current study was to evaluate the incidence of different types of epilepsy with syndromes and use of AEDs in patients with epilepsy in detail in a population, characterized by gender and age differences, with focus on exposure of AEDs, in Karachi-Pakistan. It reveals the results of a retrospective cohort study conducted during the period of June 2015 to May 2017 at General Neurology wards of different tertiary care hospitals of Karachi, Pakistan. Prescriptions $(n=90,356)$ were randomly collected along with the diagnostic data of patients with epilepsy. Variables included exposure of AEDs, polytherapy, age and gender differences, AEDs dosages and Non-AEDs in the same prescription. Total of 21 AEDs were utilized during the two-year study. Variations in the prescription pattern were noticed with respect to age and gender differences. Seventy-four percent of patients with epilepsy have utilized more than one AED. Levetiracetam (38\%) was the most prescribed drug among all AEDs used in hospitals of Karachi, Pakistan. Valproic acid was still the most commonly utilized AED in children after inclusion its name in black box warning drug list. This study revealed the discrepancies related to dosages of commonly prescribed AEDs. The study indicates higher prevalence of irrational use of AEDs and the discrepancies in the dosing of mostly drugs. The achieved outcomes may provide sufficient basis for pharmacovigilance studies to health care authorities.
\end{abstract}

\section{Rezumat}

Epilepsia este cea mai frecventă tulburare neurologică ce apare după accident vascular cerebral. Prevalența epilepsiei este de aproximativ 9,99 la 1000 locuitori în Pakistan. În ultimii ani, au fost comercializate aproximativ 14 noi medicamente antiepileptice (AEDs). Medicamentele iraţional prescrise scad complianţa pacientului la terapie și induce insuficienţă terapeutică. Scopul studiului a fost de a evalua incidența diferitelor tipuri de epilepsie şi utilizarea AEDs la pacienții cu epilepsie, în Karachi-Pakistan. Este prezentat un studiu retrospectiv de cohortă, realizat în perioada iunie 2015 - mai 2017 în secțiile de neurologie ale unor spitale din Karachi, Pakistan. Prescriptiile $(n=90.356)$ au fost colectate aleatoriu împreună cu datele de diagnostic ale pacienților. Variabilele au inclus expunerea la AEDs, politerapia, vârsta, sexul, dozele de AEDs şi non-AEDs pe aceeași prescripție. 21 de AEDs au fost utilizate pe parcursul celor doi ani de studiu. $74 \%$ dintre pacienții cu epilepsie au utilizat mai mult de un AED. Levetiracetamul (38\%) a fost cel mai prescris medicament. Acidul valproic a fost cel mai frecvent utilizat AED la copii. Acest studiu a relevat discrepanțele legate de dozele de AEDs frecvent prescrise.

Keywords: antiepileptic drugs, prescribing practices, pharmacovigilance

\section{Introduction}

Epilepsy is a brain disorder characterized by an enduring predisposition to generate unpredictable and episodic seizures. Around 50 million populations have been diagnosed with epilepsy globally [1]. It has been reported that the incidence rate of epilepsy is higher in low income countries including Pakistan (100 per 100,000). One in 100 people currently live with epilepsy in Pakistan [2]. 
Antiepileptic drugs (AEDs) have a variety of chemical constituent, and fourteen new drugs have been marketed during the last 25 years. These new drugs still acknowledge lack of safety profile related to special populations like women, elderly and children [3]. According to the WHO report, only $10 \%$ to $20 \%$ patients receive appropriate treatment. Patients nonadherence is the major issue arise during epilepsy therapy due to the undesirable side effects associated with long term use of AEDs [4]. Most of the AEDs, especially innovator brands are expensive compared to other generic brands available in market. Such higher cost of drugs also results in patient nonadherence during epilepsy treatment.

Polypharmacy and irrational drugs use directly reflected the prescribing behaviour of physicians. Drug prescribing is an art and it's indicating that how good the physicians convey a message to patients. The rational use of drugs refers to the right drug prescribed to their clinical needs in optimum dose and dosage form at the right time with affordable cost [5]. Irrational drugs prescribing are one of the leading causes of morbidity and mortality in health care practices [6]. Treatment with costly drugs may result in patient's nonadherence and also cause negative impact on health economy in every country. The prescribing patterns are mostly irrational and it is necessary to register the appropriate prescribing patterns to improve the standards of prescribing practices [7].

Prescription assessment studies have been performed by different researchers on the utilization of AEDs, in various countries that resulted in a beneficial impact on clinical settings [8-11]. Many serious errors in drugs prescribing have been found and reported in previous studies. The researchers also suggested that how to overcome these errors and improve the prescribing practices in clinical settings. Like in some other countries, irrational use of medications is a most common issue arising in Pakistan. This study aimed to evaluate the prescription of drugs by neurologists and epileptologist for the management of epilepsy in the whole population of Karachi, Pakistan. This prescription-based analysis may comprise in the pharmacovigilance process, for the detection, assessment and prevention of adverse events associated with AEDs. Several studies on prescription assessment have been reported previously with different methodology in Karachi-Pakistan [12-14]. However, according to our literature review, this is the first observational survey-based investigation in Pakistan highlighting the patterns and frequency of different AEDs used in the Neurology wards of different hospitals at Karachi, Pakistan from June 2015 to May 2017.

\section{Materials and Methods}

\section{Study design}

The collection of data was performed without the knowledge of the neurologist for studying their actual prescribing practices. This investigation was conducted in a retrospective cohort manner in Neurology ward of different tertiary care hospitals at Karachi, Pakistan, between June 2015 and May 2017. Prescription refers to a set of several lines of drugs prescribed by a medical practitioner that authorizes a specific patient to be issued with specific medicines. Pharmacists collected the photocopies of prescriptions and diagnostic data of patients with epilepsy after their consent at a dispensing time of medicines. The prescription pattern was investigated in detail using this methodology: (a) Assessment of monotherapy and polytherapy along with most prescribed combination; (b) Ratio of AEDs prescribed with respect to gender and different age group; (c) Evaluation of generic substitution; (d) Utilization of concomitant non-AEDs; (e) Dosage of AEDs. The mean AEDs dosages per day for epilepsy therapy were measured using the World Health Organization (WHO) criteria. [Ratios between the defined daily dose (DDD) and the actual prescribed daily dose (PDD)] [15]. The DDD and PDD refer to the assumed average maintenance dose and the actual prescribed maintenance dose per day for a drug used for the treatment of epilepsy respectively.

\section{Patient Population}

Data related to patients were obtained from the previous diagnostic history of the patients' profile without interviews. The local Ethics Committee at Ziauddin Hospital Karachi, Pakistan approved the study. For each patient profile selected, the following information was abstracted: medical history, demographics, physical examination, educational and social status, types of epilepsy and any other co-morbidity. For this study, we collected a total of 90,356 (n) prescriptions along with diagnostic data from patients with epilepsy homogeneously distributed throughout Karachi. All selected patients enrolled in this study fulfilled the following eligibility criteria: (i) confirmed diagnosis of epilepsy from laboratory profile of those patients and taking one or more AEDs; (ii) at least one seizure episode was occurred during the previous 6 months with a currently used regimen of AEDs; (iii) filled consent form. The patients with epilepsy were monitored during their course of treatment to evaluate the AED switches and changes in dosing of AEDs.

Statistical analysis

All obtained data were expressed as their means \pm standard deviations ( $\overline{\mathrm{X}} \pm$ S.D.) and percentages. Statistical analysis was performed to assess the study significance using the SPSS program (version 23). Independentsamples $t$-test was used to compare the differences between each AED utilized as monotherapy or polytherapy in relation to different variables. The achieved 
data were analysed and compared at a significance level of 0.05 .

\section{Results and Discussion}

Characteristic of the study group

A total of 90,356 patients, including 78,452 adults (mean age of 35 years), and 11,904 children (mean age of 7 years) were enrolled in this investigation. According to the data collected from patient diagnostic profiles, most adult patients $(61.6 \%)$ had partial epilepsy while most children had $(5.4 \%)$ generalized epilepsy. Comorbidities (psychiatric and neurological) were also associated in selected patients i.e. $30 \%$ in adults while $18 \%$ in children. The demographic distribution detail regarding the epilepsy types and its syndromes in study population is presented in Table I.

Table I

Demographic data of epilepsy types and its syndromes in study population with respect to age and gender

\begin{tabular}{lcccc}
\hline \multirow{2}{*}{ Indication for use } & \multicolumn{2}{c}{ Age group in years } & \multicolumn{2}{c}{ Gender } \\
\cline { 2 - 5 } & Adult & Children & Male & Female \\
\hline Partial epilepsy & $55,700 *(61.6 \%)$ & $2,619(2.9 \%)$ & $33,612(37.2 \%)$ & $25,214(27.9 \%)$ \\
Generalized epilepsy & $11,939(13.2 \%)$ & $4,882(5.4 \%)$ & $9,035(10 \%)$ & $7,499(8.3 \%)$ \\
Idiopathic generalized epilepsy & $6,730(7.4 \%)$ & $1,428(1.6 \%)$ & $4,608(5.1 \%)$ & $3,433(3.8 \%)$ \\
Cryptogenic generalized epilepsy & $4,083(4.5 \%)$ & $1,904(2.1 \%)$ & $3,433(3.8 \%)$ & $2,529(2.8 \%)$ \\
Benign rolandic epilepsy & $0(0 \%)$ & $1,071(1.1 \%)$ & $542(0.6 \%)$ & $451(0.5 \%)$ \\
Total & $\mathbf{7 8 , 4 5 2 ( 8 6 . 8 \% )}$ & $\mathbf{1 1 , 9 0 4}(\mathbf{1 3 . 1 \%})$ & $\mathbf{5 1 , 2 3 0 ( 5 6 . 7 \% )}$ & $\mathbf{3 9 , 1 2 6 ( 4 3 . 3 \% )}$ \\
*Number of Patients; **Total number of prescriptions $=90,356$ & & &
\end{tabular}

Prescribing pattern of AEDs

Polytherapy

A total of 21 AEDs were prescribed in neurology ward of different tertiary care centre at Karachi, Pakistan. Polytherapy was highly prevalent, with $81 \%$ of adults and $68 \%$ of children being received a combination of two or more AEDs for their treatment. Levetiracetam $(38 \%)$, valproic acid (29\%) and carbamazepine (22\%) were the most commonly prescribed AEDs in patients with epilepsy as indicated in Figure 1. The most frequently used combination of AEDs in all study patients with epilepsy was carbamazepine and phenytoin $(48 \%)$. It should be noted that levetiracetam and carbamazepine was the second most frequently used combination in adult $(25 \%)$, which is accounted as polypharmacy.

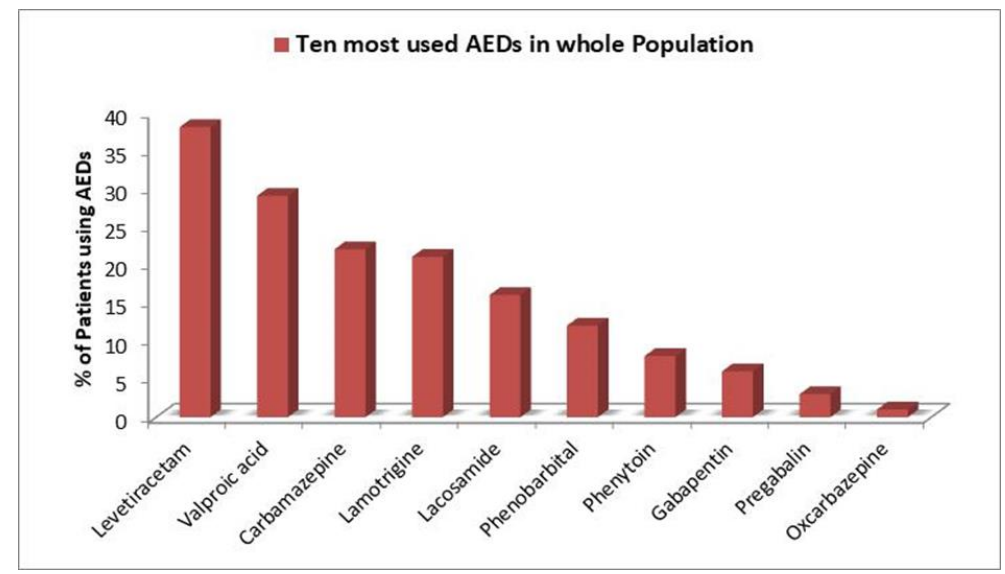

Figure 1.

Frequency of 10 most commonly prescribed AEDs used as monotherapy or polytherapy in the studied population

Table II

Levetiracetam utilization and generic substitution in epilepsy patients

\begin{tabular}{lc}
\hline & Number of epilepsy patients \\
\hline Patients who used levetiracetam for epilepsy & \\
Actual number of epilepsy patients/ Total prescriptions & $34,335 * / 90,356$ \\
Percentage of patients used & $38.0 \%$ \\
Patients who received same medication & \\
Patients who received Lerace ${ }^{\circledR}$ & $14,423(42 \%)$ \\
Patients who used other brands of levetiracetam & $13,805(40.2 \%)$ \\
Patients who received generic levetiracetam products & $29(0.08 \%)$ \\
Patients who switched to levetiracetam & $6,078(17.7 \%)$ \\
Percentage of switches in prescription/Total prescriptions & $6.72 \%$ \\
\hline
\end{tabular}


Generic substitution

Generic substitution of AEDs during epilepsy therapy is a serious issue. In our study levetiracetam was chosen for the assessment of generic substitution being the most prescribed AED. In $17.7 \%$ of the patients with epilepsy, substitution of generic was found during the therapy of epilepsy and all were switched to levetiracetam from other AEDs during the two-year period. However, the majority of patients with epilepsy received the original product Lerace ${ }^{\circledR}$ as given in Table II.

Gender impact on AEDs utilization

Differences in the utilization of ten most frequently prescribed AEDs between male and female are presented in Figure 2, where male and female patients received $53 \%$ and $47 \%$ of AEDs respectively. Levetiracetam was the most prescribed AED in both male and female. Valproic acid (42\% vs. $31 \%, \mathrm{p}=0.004)$, lamotrigine $(37 \%$ vs. $18 \%, \mathrm{p}=0.0006)$ and gabapentin $(23 \%$ vs $12 \%, \mathrm{p}=0.0002)$ were received to a larger extent in female, while pregabalin ( $56 \%$ vs. $36 \%, \mathrm{p}=0.0001$ ), phenytoin $(30 \%$ vs. $12 \%, \mathrm{p}=0.00009)$ and phenobarbital ( $33 \%$ vs. $21 \%, \mathrm{p}=0.0001$ ) were the most commonly used AEDs in male. The prescribing ratios of clobazam, oxcarbazepine and lacosamide were almost similar in male and female. No gender differences were observed in the used of two or more AEDs in combination.

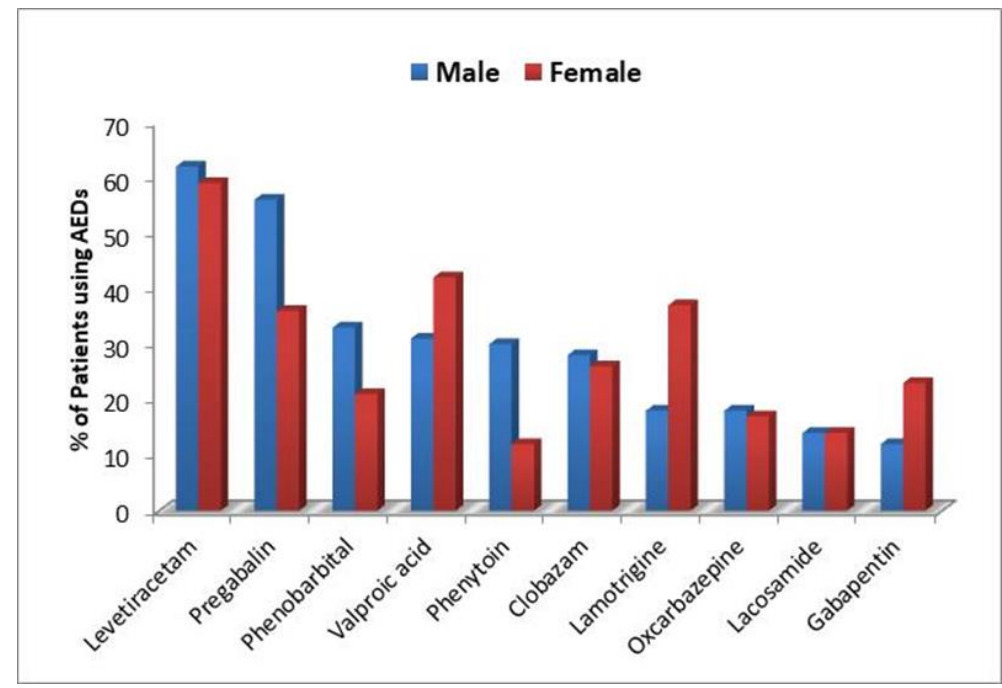

Figure 2.

Relative frequency of AEDs utilization as monotherapy or polytherapy with respect to genders

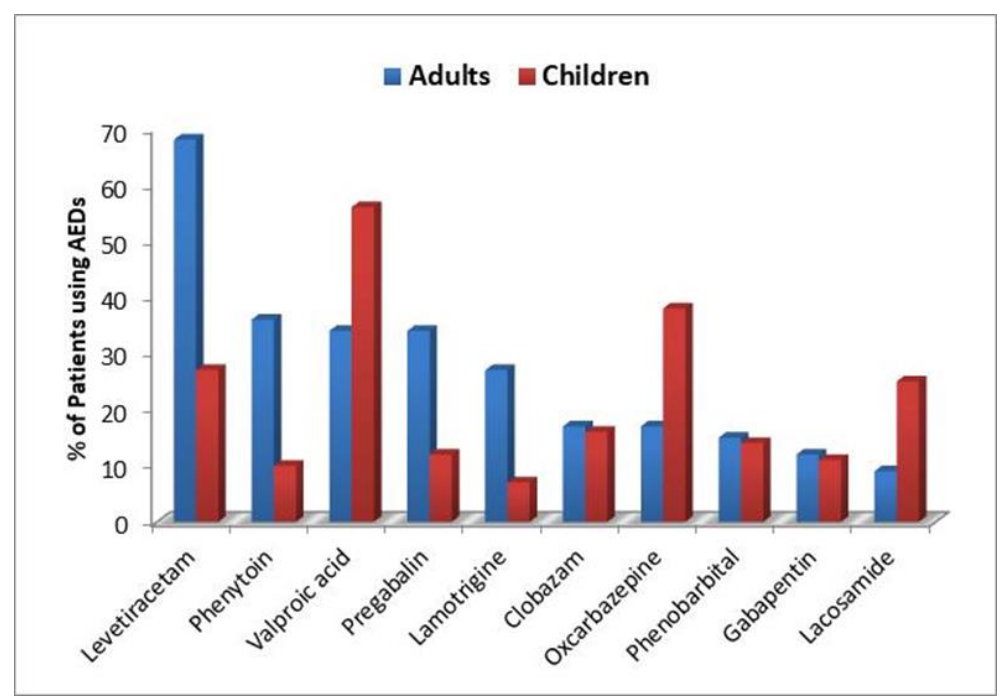

Figure 3.

Relative frequency of AEDs utilization as monotherapy or polytherapy with respect to age

Age impact on AEDs utilization

The data of collected prescriptions with respect to different age groups are described above and also presented in Table I. There were significant differences in the used of ten most frequently prescribed AEDs with respect to different age groups as shown in Figure 3. The most prescribed AEDs in children were valproic acid (56\% vs. $34 \%$, 
FARMACIA, 2019, Vol. 67, 6

$\mathrm{p}=0.003)$ and oxcarbazepine $(38 \%$ vs. $17 \%, \mathrm{p}=$ $0.0001)$ while levetiracetam $(68 \%$ vs. $27 \%, \mathrm{p}=0.0006)$ and lamotrigine ( $27 \%$ vs. $7 \%, \mathrm{p}=0.00001)$ were used more in adults. The use of phenytoin and pregabalin increased in older age patients after levetiracetam. However, the use of oxcarbazepine and lacosamide were restricted to patients of youngest age group after valproic acid. No age differences were observed in the used of clobazam, phenobarbital and gabapentin. Valproic acid and lamotrigine was the most frequently used combination in adolescent patients while, levetiracetam and carbamazepine combination was more utilized in adult and oldest patients.

AEDs Daily Dosages

There were 21 AEDs included, eight of them are considered as older ( $1^{\text {st }}$ generation) and 13 are regarded as newer AEDs. The correlation ratios between the DDD and PDD of each AED were used. Ratios near to 1.0 consider to a good correlation between dosages of AEDs in theory and in actual clinical use. The mean ratios of all AEDs dosages prescribed per day (means \pm S.D) as monotherapy or polytherapy are presented Figures 4 and 5. The mean ratios of all prescribed AEDs dosages were within range of 0.24 1.46. Most AEDs were used in similar dosages ratios in monotherapy or polytherapy except clobazam and valproic acid which were prescribed at higher dosages ratio when received as monotherapy. Clonazepam was given at lower dosages ratio (0.24) while levetiracetam prescribed at higher dosages (1.46) when used as polytherapy.

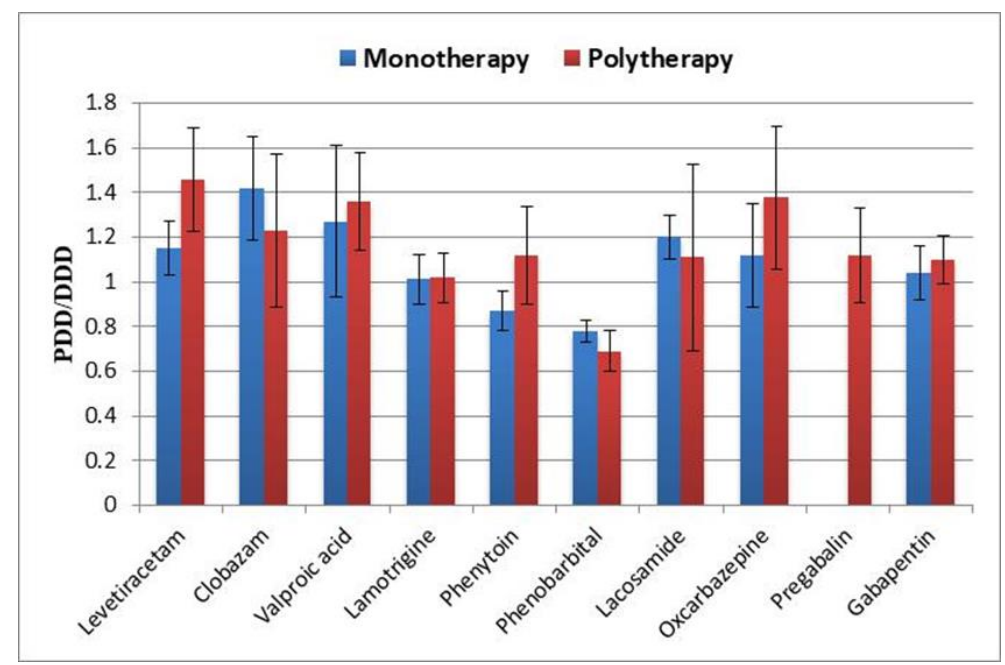

Figure 4.

Daily dosages ratios (means \pm SD) of 10 most commonly prescribed AEDs used as monotherapy or polytherapy

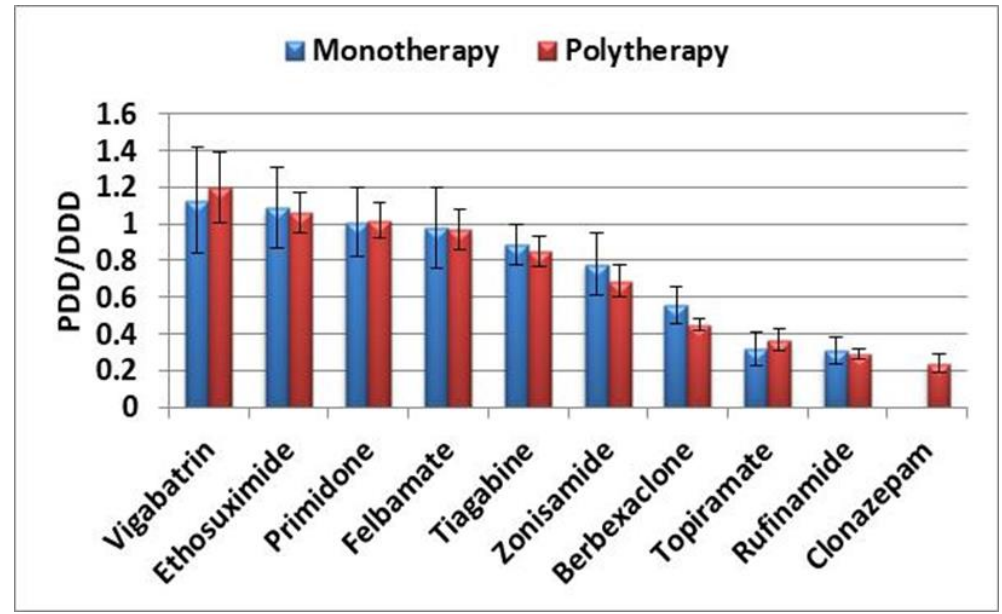

Figure 5.

Daily dosages ratios (means \pm SD) of 10 least commonly prescribed AEDs used as monotherapy or polytherapy

\section{Non-AEDs concomitant therapy}

Concomitant non-AED therapy was not used for epilepsy but rather in patients with epilepsy for other comorbidities. About $35.8 \%$ of adults and $27 \%$ of children were using non-AEDs for other indications during epilepsy treatment. The most common nonAEDs drugs prescribed in adults were antidepressants (11.6\%), antipsychotics (7.4\%), anxiolytic and hypnotic 
FARMACIA, 2019, Vol. 67, 6

agents $(6.2 \%)$. In children, antiemetics (7.6\%) and antiulcer $(4.3 \%)$ were the most co-prescribed non-AEDs in the treatment of epilepsy after food supplements i.e. $11.6 \%$ (Table III).

Table III

Ratio of concomitant non-AEDs prescribed in the same prescription

\begin{tabular}{|c|c|c|}
\hline Class of drugs* & $\begin{array}{c}\text { Adults } \\
\left(n=78,452^{* *}\right) \\
\end{array}$ & $\begin{array}{c}\text { Children } \\
(n=11,904) \\
\end{array}$ \\
\hline Antidepressants & $9,100(11.6 \%)$ & $130(1.1 \%)$ \\
\hline Duloxetine & $4,550(5.8 \%)$ & $60(0.5 \%)$ \\
\hline Citalopram & $1,696(3.5 \%)$ & $12(0.1 \%)$ \\
\hline Antipsychotics & $5,805(7.4 \%)$ & $119(1.0 \%)$ \\
\hline Aripiprazole & $1,961(2.5 \%)$ & $38(0.3 \%)$ \\
\hline Haloperidol & $1,412(1.8 \%)$ & $24(0.2 \%)$ \\
\hline Anxiolytic and hypnotic & $4,864(6.2 \%)$ & $166(1.4 \%)$ \\
\hline Alprazolam & $2,667(3.4 \%)$ & $24(0.2 \%)$ \\
\hline Diazepam & $1,333(1.7 \%)$ & $71(0.6 \%)$ \\
\hline Antiemetics & $1,647(2.1 \%)$ & $904(7.6 \%)$ \\
\hline Metoclopramide & $862(1.1 \%)$ & $250(2.1 \%)$ \\
\hline Domperidone & $314(0.4 \%)$ & $523(4.4 \%)$ \\
\hline Antiulcer & $1,412(1.8 \%)$ & $511(4.3 \%)$ \\
\hline Omeprazole & $628(0.8 \%)$ & $333(2.8 \%)$ \\
\hline Aluminum Hydroxide and Magnesium Hydroxide & $314(0.4 \%)$ & $119(1.0 \%)$ \\
\hline Food supplements & $5,256(6.7 \%)$ & $1,380(11.6 \%)$ \\
\hline Vitamin D & $1,804(2.3 \%)$ & $440(3.7 \%)$ \\
\hline Vitamin B & $941(1.2 \%)$ & $231(2.7 \%)$ \\
\hline Folic Acid & $1,647(2.1 \%)$ & $500(4.2 \%)$ \\
\hline Melatonin & $235(0.3 \%)$ & $48(0.4 \%)$ \\
\hline
\end{tabular}

*Class of non AEDs along with most used drugs from each class; **Number of Patients

Our demographic data reflects the prevalence of different types of epilepsy and its syndromes during the two-year study period. The incidence of generalized epilepsy in children was much higher as compared to previous studies $[2,9,10]$. This study demonstrates a prevalence of polytherapy similar to the previous studies conducted in different countries as Norway and Italy with different methodologies. The obtained results of this study indicate the high incidence of polytherapy in both adult (81\%) and children $(68 \%)$ than reported in Norway or similar with Italy $[8,16]$. This higher incidence of polytherapy is a concern, particularly since major drug interactions were reported with the most frequently prescribed AEDs such as levetiracetam, valproate, carbamazepine and lamotrigine [17]. Additionally, polytherapy may increase the risk of drug interactions, adverse effects or alteration in the metabolism of drugs. The extensive use of more than one AED can be explained partly by an increased use of newer AEDs, in which most of them are approved for add-on use only. Monotherapy is preferred if possible, but during therapy not all patients with epilepsy will achieve effective control on seizure using single AED. The combination of carbamazepine and phenytoin was most frequently used since it was a deemed safe combination according to a reference from the pre-new AED era [18]. Pregabalin was prescribed only in combination with other AEDs. Individualization of optimal therapy and improved patients' compliance may be achieved by performing the therapeutic drug monitoring of each AED [19].
Generic substitution in epilepsy therapy is a major issue and may cause potential adverse reactions or seizure relapse [20]. As presented, we found substitution of generic during epilepsy therapy regarding $17.7 \%$ $(6,078$ out of 90,356 patients) of levetiracetam prescriptions for two years, despite of the restricted generic substitution due to the pharmacological variability of different AEDs in patients with epilepsy. Our study also showed that 28,841 patients received a single product with levetiracetam that is "Lerace ${ }^{\circledR}$ ", becoming the most prescribed brand of AED during 2015 to 2017. In line with this result, showing how promotional strategies of different pharmaceuticals influenced the use of levetiracetam by neurologists, the European Medicines Agency (EMA) highlighted the importance of bioequivalence studies of the marketed brands and has introduced the more strict limits of bioequivalence studies for marketed products $(90 \%-100 \%$ instead of $85 \%-125 \%)$ [21].

Investigation of prescribing behaviour in relation to the patients' individual characteristics yielded important clues for the evaluations of AED prescription. In accordance with previous studies, there were significant differences in the use of AEDs between male and female [8]. Lamotrigine seem to be used for female more frequently than male, may be due to its less teratogenic effects. The prescribing ratio of phenytoin was much lesser in the females and could be related to phenytoin associated cosmetic side effects, including gingival hyperplasia and hirsutism. However, this justification could be in conflict with the finding regarding the higher utilization of valproic acid in 
females, which is associated with teratogenic effects $[22,23]$. Obesity is also a commonly arising adverse effect of valproic acid and it is a serious concern in female patients. Oxcarbazepine was used to a virtually identical extent in both genders, although greater utilization of this drug in females was reported in Norwegian study [24].

There were significant differences in the prescribing pattern of all AEDs in different age group patients. The more frequently use of valproic acid in young children is may be related to the higher prevalence of generalized epilepsies in low age patients as indicated in our demographic data. However, valproic acid use should be avoided after its inclusion in black box warning drug list [25]. The extensive use of levetiracetam in adults is probably related to its safety profile data reported in young age population. Phenytoin and pregabalin are now most frequently prescribed AED in elderly patients. However, it should be noted, that the enzyme induction and nonlinear pharmacokinetics associated with phenytoin that is a serious concern in elderly patients [26]. The pharmacokinetic properties of most AEDs are altered in older age patients, often with low and high clearance in the elderly and children respectively.

The defined daily doses (DDDs) for all AEDs are an estimate and it is not always similar with the actual prescribed doses. The estimation of an actual prescribing dose of individual AED as compared to recommended dose is an important tool for assessing the rational drug usage. Our findings show the major discrepancies between the actual prescribing daily dosages and the defined daily dosages (DDD) per day during two-year study. The used of clonazepam in very low dosages $(0.24)$ than the theoretical doses, which is a critical issue may result in sub-therapeutic effects of drug. Conversely, levetiracetam is the most prescribed AED in Pakistan but in fact it is received at higher dosages (1.46) as polytherapy. More importantly, it was also observed that no dosages alteration found with respect to age, gender or used as a monotherapy or polytherapy except for few AEDs. This variability in dosing of AEDs in relation to the specific patients' group was also reported by Landmark et al. in 2007 [24]. The results of this study could contribute to the better implementation of WHO recommended DDDs for each AED.

Comorbidities were seen higher in patients with epilepsy especially depression and psychosis found in refractory epilepsy patients [27]. This is also indicated in our findings that about half of the adults and one-third of children were using non-AEDs prescribed for other indications. The used of concomitant drugs in children was less commonly and focused on the main indication to avoid drug interactions and adverse or side effects.
Strength and Limitation

As told before, it is the first survey-based observational study in Karachi, Pakistan that provides data about both incidence of epilepsy and prescribing pattern of AEDs in neurology wards of different tertiary care centres. Another strength of our study is the updated availability of patient's clinical information regarding the indication of AED use, in the collected data source. However, several limitations of this study have to be addressed. First, we extract data from prescriptions and diagnostic profiles of outpatients, and we had no information regarding the actual filling of AEDs and also use of these prescribed drugs. Although, this investigation was mainly focused on evaluating the prescribing pattern of different AEDs with no consideration to the clinical outcomes of drugs. Second, this study was conducted using prescribing data from a restricted area of Pakistan i.e. Karachi. Therefore, it may be possible that these outcomes could not reflect the prescribing practices in whole Pakistan. However, the reliability of extracted data for this study was also supported by Intercontinental Marketing Services (IMS) black book. IMS Health is known for its collection of data about healthcare information like sales of pharmaceutical products worldwide and also in whole Pakistan.

\section{Conclusions}

The data of most and least commonly prescribed AEDs in the whole population of Karachi, Pakistan, were presented in this study. All AEDs analysed in this study showed variability in utilization with respect to different age and gender of patients. Levetiracetam was the most prescribed AED among overall population while valproate was most frequently used in children. The study indicates that practice of polypharmacy is much higher for the treatment of epilepsy. This study also reveals the discrepancies related to dosages of most AEDs. Moreover, it was also observed during the study that there was no Epileptologist present in Neurology ward of any tertiary care hospital. These outcomes of this investigation may provide sufficient knowledge about pharmacovigilance to healthcare authorities to improve treatment of epilepsy and prescribing pattern of AEDs in clinical settings.

\section{Acknowledgement}

The authors gratefully thankful to the Higher Authorities of different tertiary care hospitals located in Karachi, Pakistan for the permission to collect data and supporting this study. We are also thankful to IMS Health Agency, for sharing the data regarding sales of pharmaceutical products of epilepsy in whole Pakistan.

\section{Conflicts of Interest}

The authors declare no conflict of interest. 


\section{References}

1. World Health Organization, Epilepsy fact sheet. 2017; www.who.int.

2. Aziz H, Ali SM, Frances P, Khan MI, Hasan KZ, Epilepsy in Pakistan: A population-based epidemiologic study. Epilepsia, 1994; 35(5): 950-958.

3. Mula M, Emerging drugs for focal epilepsy. Exp Opin Emerg Drugs, 2018; 23(3): 243-249.

4. Ettinger $\mathrm{AB}$, Argoff $\mathrm{CE}$, Use of antiepileptic drugs for nonepileptic conditions: psychiatric disorders and chronic pain. Neurotherapeutics, 2007; 4(1): 75-83.

5. World Health Organization, Essential medicines and health products. 2012; www.who.int.

6. Ramsay LE, Bridging the gap between clinical pharmacology and rational drug prescribing. $\mathrm{Br} \mathrm{J}$ Clin Pharmacol., 1993; 35(6): 575-576.

7. Bennadi D, Self-medication: A current challenge. $J$ Basic Clin Pharm., 2013-2014; 5(1): 19-23.

8. Landmark CJ, Fossmark H, Larsson PG, Rytter E, Johannessen SI, Prescription patterns of antiepileptic drugs in patients with epilepsy in a nation-wide population. Epilepsy Res., 2011; 95(1-2): 51-59.

9. Malerba A, Ciampa C, De Fazio S, Fattore C, Frassine B, La Neve A, Pellacani S, Specchio LM, Tiberti A, Tinuper P, Perucca E, Patterns of prescription of antiepileptic drugs in patients with refractory epilepsy at tertiary referral centres in Italy. Epilepsy Res., 2010; 91(2-3): 273-282.

10. Savica R, Beghi E, Mazzaglia G, Innocenti F, Brignoli O, Cricelli C, Caputi AP, Musolino R, Spina E, Trifirò G, Prescribing patterns of antiepileptic drugs in Italy: a nationwide population-based study in the years 2000-2005. Eur J Neurol., 2007; 14(12): 1317-1321.

11. Oun A, Haldre S, Mägi M, Use of antiepileptic drugs in Estonia: an epidemiologic study of adult epilepsy. Eur J Neurol., 2006; 13(5): 465-470.

12. Asghar MA, Mumtaz N, Asghar MA, Niaz S, Zaheer $\mathrm{K}$, Raza L, Prescribing behaviour of practitioners in public and private hospitals in Pakistan evaluated using the World Health Organization (WHO) indicators: A comparative approach. Pharm Hosp Clin., 2017; 52: 299-305

13. Ahmad B, Khan F, Ahmed J, Cha SB, Shin M, Bashir $\mathrm{S}$, Yoo HS, Antibiotic resistance pattern and molecular epidemiology of methicillin-resistant Staphylococcus aureus colonization in burns unit of a tertiary care hospital in Peshawar, Pakistan. Trop J Pharm Res., 2014; 13(12): 2091-2099.

14. Aqeel T, Shabbir A, Basharat H, Bukhari M, Mobin S, Shahid H, Waqar SA, Prevalence of selfmedication among urban and rural population of
Islamabad, Pakistan. Trop J Pharm Res., 2014; 13(4): 627-633.

15. World Health Organization, ETC/DDD Index. 2016; www.whocc.no.

16. Alexandre VJr, Capovilla G, Fattore C, Franco V, Gambardella A, Guerrini R, La Briola F, Ladogana M, Rosati E, Specchio LM, Striano S, Perucca E; SOPHIE Study Group, Characteristics of a large population of patients with refractory epilepsy attending tertiary referral centers in Italy. Epilepsia, 2010; 51(5): 921-925.

17. Johannessen Landmark C, Patsalos PN, Drug interactions involving the new second-and third-generation antiepileptic drugs. Exp Rev Neurother., 2010; 10(1): 119-140.

18. Mattson RH, Cramer JA, Collins JF, Smith DB, Delgado-Escueta AV, Browne TR, Williamson PD, Treiman DM, McNamara JO, McCutchen CB, Homan RW, Crill WE, Lubozynski MF, Rosenthal NP, Mayersdorf A, Comparison of carbamazepine, phenobarbital, phenytoin, and primidone in partial and secondarily generalized tonic-clonic seizures. N Engl J Med., 1985; 313(3): 145-151.

19. Johannessen SI, Landmark CJ, Value of therapeutic drug monitoring in epilepsy. Exp Rev Neurother., 2008; 8(6): 929-939.

20. Bialer M, Midha KK, Generic products of antiepileptic drugs: a perspective on bioequivalence and interchangeability. Epilepsia, 2010; 51(6): 941-950.

21. European Medicine Agency, Committee for medicinal products for human use (CHMP), Guideline on the investigation of bioequivalence. 2010; www.ema. europa.eu.

22. Tomson T, Battino D, Teratogenic effects of antiepileptic medications. Neurol Clin., 2009; 27(4): 993-1002.

23. Perucca E, Pharmacological and therapeutic properties of valproate. CNS Drugs, 2002; 16(10): 695-714.

24. Landmark CJ, Rytter E, Johannessen SI, Clinical use of antiepileptic drugs at a referral centre for epilepsy. Seizure, 2007; 16(4): 356-364.

25. Zarowitz BJ, Black box warnings - Implications in practice. Geriatr Nurs., 2008; 29(6): 402-409.

26. Bergey GK, Initial treatment of epilepsy: special issues in treating the elderly. Neurology, 2004; 63(10 Suppl.4): S40-S48.

27. Hermann B, Seidenberg M, Jones J, The neurobehavioural comorbidities of epilepsy: can a natural history be developed?. Lancet Neurol., 2008; 7(2): 151-160. 